\title{
Platelet count and MPV in women with PIH in their third trimester
}

\author{
Suhail Iqbal*, Aditi Sharma
}

Department of Obstetrics and Gynecology, Jhalawar Medical College, Jhalawar, Rajasthan, India

Received: 04 September 2018

Revised: 06 October 2018

Accepted: 19 December 2018

\section{*Correspondence:}

Dr. Suhail Iqbal,

E-mail: isuhaillove@gmail.com

Copyright: ( $)$ the author(s), publisher and licensee Medip Academy. This is an open-access article distributed under the terms of the Creative Commons Attribution Non-Commercial License, which permits unrestricted non-commercial use, distribution, and reproduction in any medium, provided the original work is properly cited.

\begin{abstract}
Background: One of the most common and potential life-threatening complications of pregnancy is pregnancy induced hypertension. Though platelet count during pregnancy is within the normal non-pregnant reference values, there is a tendency for the platelet count to fall in late pregnancy. The frequency and intensity of maternal thrombocytopenia varies and is dependent on the intensity and severity of PIH.

Methods: This prospective study was conducted in the Department of obstetrics and gynecology in Jhalawar medical college from January 2018 to April 2018.Total 120 pregnant women during third trimester (32-40 weeks) aged 18 to 35 years were selected. Among them 63 were preeclamptic patients and 63 were healthy normotensive control. Subjects and healthy pregnant women (control) visiting the Obstetrics and Gynecology department of Jhalawar Medical College were registered in the study and followed during their pregnancy. Both, subjects and control participants were subject to platelet count manually and MPV was determined by an automated analyser (sysmex XN$1000^{\mathrm{TM}}$ ) performed using standard methods on.

Results: The mean platelet count of the subject group $\left(131.4937 \pm 62.05999 \mathrm{lakh} / \mathrm{mm}^{3}\right)$ was significantly lower than that of the control group $(324.9683 \pm 230.78764 \mathrm{lakh} / \mathrm{mm} 3)$. This shows that there is thrombocytopenia found in patients with P.I.H in their third trimester. On the other hand, the $\mathrm{p}$ value of "mean platelet volume" in patients with preeclampsia was $(p<0.0001)$ which shows that there is no significant difference in MPV of cases $(7.1438 \pm 2.62$ femtolitre) and control (7.8976 \pm 3.08 femtolitre) ( $>>0.142)$, regular monitoring of platelet counts in women with Pregnancy Induced Hypertension must be subject of the management protocols.

Conclusions: In present study we observed that the number of thrombocytopenic subjects was higher in cases of preeclampsia as compared to the control group. These extrapolations indicate that there might be some important mechanism which interferes with platelets life span thus reducing the number of functional platelets in circulation. The platelet count has an association at prediction of increasing grade of PIH. There is an inverse relationship between the severity of PIH and platelet count. The depleted platelet counts are concluded to be consistently associated with clinical groups of severe preeclampsia and the risk of consumptive coagulopathy.
\end{abstract}

Keywords: fL (femtolitre), Hypertension, MPV (Mean platelet volume), Platelet count, Pregnancy

\section{INTRODUCTION}

Pregnancy is a physiological process but can induce hypertension in normotensive women or aggravate already existing hypertension. Preeclampsia, the most common of hypertensive disorders of pregnancy is an idiopathic multisystem disorder affecting 2-10\% of all pregnancies and together they form one member of the deadly triad, along with haemorrhage and infection that contribute greatly to the maternal morbidity and mortality rates. ${ }^{1}$ The identification of this clinical entity and effective management play a significant role in the 
outcome of pregnancy. Normal pregnancy is associated with impressive changes in the haemostatic mechanism to maintain placental function during pregnancy and to prevent excessive bleeding in delivery. The combined changes of increase coagulation factors and suppression of fibrinolytic activity are defined as hypercoagulable state or prothrombotic state. ${ }^{2,3}$ It usually occurs in the last trimester of pregnancy and more commonly in primiparas. It is characterized by maternal endothelial dysfunction presenting clinically with hypertension and proteinuria, and results in hypercoagulable state and may lead to acute renal failure (ARF), pulmonary oedema and approximately $10 \%$ of woman with severe preeclampsia may developed, hemolysis, elevated liver enzyme and low platelet count referred to as HELLP syndrome. ${ }^{4}$

The endothelial dysfunction develops because of the formation of uteroplacental vasculature insufficient to supply adequate blood to the developing fetus resulting in fetoplacental hypoxia leading to imbalances in the releases and metabolism of prostaglandins, endothelin and nitric oxide by placental and extra placental tissue. These as well as enhanced lipid peroxidation and other undefined factors contribute to the hypertension platelet activation and systemic endothelial dysfunction. 5 Many haemostatic abnormalities have been reported in association with hypertensive disorder of pregnancy. Thrombocytopenia is most common of these abnormalities. ${ }^{6}$ The degrees of thrombocytopenia increases with severity of disease. ${ }^{7}$ Thrombocytopenia in preeclampsia is attributed to various causes including increases platelet consumption due to disseminate intravascular coagulopathy and/or immune mechanism. ${ }^{8}$

Most of the studies observed significant decrease in platelet count during normal pregnancy. ${ }^{9}$ There is a significant decrease in platelet count especially during second and third trimesters. Thrombocytopenia can result from decrease in platelet production or accelerated platelet destruction. The various mechanisms of thrombocytopenia in pregnancy explained by different workers are as under:

- Hemodilution in late pregnancy. ${ }^{10}$

- Decreased platelet survival time during normal pregnancy. ${ }^{11}$

- Plasma beta thromboglobulin and platelet factor 4 levels, both reflecting platelet activation, were significantly increased during normal pregnancy, indicating an increase in platelet activation, and supporting the hypothesis that there is an increased turnover of platelets during the progression of normal pregnancy. ${ }^{12}$

Hence the study is aimed to analyse the utility of platelet count in pre-eclampsia so as to prevent complication, early detection, careful monitoring and appropriate management to reduce the morbidity and mortality of both mother and child. The aim of the study was to see the platelet count in pregnancy induced hypertension
(PIH). It was a prospective study. This study is aimed to investigate the relationship between platelet count and MPV (Mean platelet volume) in pregnancy induced hypertension patients in their 3rd trimesterTo study Platelet count and mean platelet volume in cases of Pregnancy induced hypertension and to correlate and compare the values with Normotensive pregnant subjects. All the necessary information and data were collected by interviewing the patients or their attendants on a predesigned data collection sheet. Blood sample were collected from the patients and required investigations were done. Although there is chance of development of disseminated intravascular coagulation (DIC) and Liver Failure in patients with low platelet count, but in present study there is no such incidence.

\section{METHODS}

This present study was carried out at the Obstetrics and Gynaecology department Jhalawar medical college Jhalawar district, Rajasthan 2018 (September). The preliminary data in regard to name, age, sex, registration number, obstetric, menstrual, and family history, general and systemic examination and investigations were recorded in a proforma after getting informed consent from the patients. The subjects for this study included consecutively-recruited Sixty-Three (63) pregnant women with hypertension (PIH) and proteinuria. SixtyThree (63) subjects without PIH served as a control. Two millilitres of blood sample was drawn aseptically using the $5 \mathrm{ml}$ syringe from the median ante-cubital vein of all the subjects and control participants into EDTA-ant coagulated tubes. Platelets were counted manually under high field microscope by sending samples to the pathology department at Jhalawar medical college.

\section{Inclusion criteria}

- Age 18-35 years,

- Preeclamptic women whose blood pressure was normal during first 20 weeks of gestation

- No previous history of hypertension and all the case were in the third trimester of pregnancy.

- $\quad \mathrm{BP}>140 / 90$ with proteinuria (proteinuria $+1,+2,+3$ or+4) on dipstick test.

\section{Exclusion criteria}

- Subjects with haemorrhagic disorders,

- Sepsis,

- Functional uterine bleeding,

- Placental abruption or previa,

- Diabetes, respiratory, circulatory, renal and hepatic disorders,

- Known cases of hypertension

- Gestational thrombocytopenia

- Immune thrombocytopenia

- Subjects taking drugs which can affect platelet count were excluded from the study. 


\section{Statistical analysis}

Statistical analysis was performed with the SPSS, Trial version 23 for Windows statistical software package (SPSS inc., Chicago, il, USA) and Primer. The Categorical data were presented as numbers (percent) and were compared among groups using Chi square test. The quantitative data were presented as mean and standard deviation and were compared using by students t-test and ANOVA Test .Probability $\mathrm{P}$ value 25 years subjects dominated in severe preeclampsia group.

\section{RESULTS}

In present study total no of 126 patients were taken, divided into two groups. Each group containing 63 patients. The groups were divided into cases (63 patients) and cases (63 patients).

The age group which we took for present study was between 18 to 35 years of age. The mean age for cases was 27.50 and the mean age for control group was 28.36 with a standard deviation of 3.1 and 2.7 respectively. The results showed that there was no significant difference in age between cases and control ( $p>0.05)$. It means study is age matched (Table 1).

Table 1: Distribution of age according to groups.

\begin{tabular}{|c|c|c|c|c|c|c|}
\hline & Group & $\mathbf{N}$ & $\begin{array}{l}\text { Mean } \\
\text { age }\end{array}$ & $\begin{array}{l}\text { Std. } \\
\text { deviation }\end{array}$ & $\begin{array}{l}\mathrm{T} \\
\text { value }\end{array}$ & $\begin{array}{l}\mathbf{P} \\
\text { value }\end{array}$ \\
\hline \multirow{2}{*}{ Age } & Case & 63 & 27.50 & 3.18 & \multirow{2}{*}{1.619} & \multirow{2}{*}{0.108} \\
\hline & Control & 63 & 28.36 & 2.74 & & \\
\hline
\end{tabular}

The mean platelet count of the subject group $(131.4937 \pm 62.05999)$ was significantly higher when compared to that of the control group (324.9683 \pm 230.78764$)$. The $P$ value is $<0.0001$ which is $<0.05$. This shows that there is significant co-relation between PIH and platelet count which is with increase in B.P of a patient, platelet count decreases (Inverse relationship) (Table 2).

Table 2: Distribution of platelets according to groups.

\begin{tabular}{|l|l|l|l|l|l|l|}
\hline \multirow{2}{*}{ Platelets } & Group & N & Mean platelet $\left(\right.$ lakh/ $\left./ \mathrm{mm}^{3}\right)$ & Std. deviation & T value & P value \\
\cline { 2 - 8 } & Case & 63 & 131.4937 & 62.05999 & 6.426 & $<0.0001$ \\
\cline { 2 - 7 } & Control & 63 & 324.9683 & 230.78764 & & \\
\hline
\end{tabular}

Table 3: Distribution of MPV according to groups.

\begin{tabular}{|c|c|c|c|c|c|c|}
\hline & Group & $\mathbf{N}$ & Mean platelet volume (femtolitre) & Std. Deviation & T value & P value \\
\hline MPV & Case & 63 & 7.1438 & 2.62068 & \multirow{2}{*}{1.479} & \multirow{2}{*}{0.142} \\
\hline MPV & Control & 63 & 7.8976 & 3.08140 & & \\
\hline
\end{tabular}

When compared mean platelet volume of cases and control group. The mean platelet volume of cases and control group was found to be $(7.1438 \pm 2.62068)$ and (7.8976 \pm 3.08140$)$ respectively.

The $p$ value was found to be $p>0.142$, which is $>0.05$ and thus no significant relationship was found in MPV of cases and controls. Although various previous studies have shown inverse relationship of MPV between cases and controls (Table 3). Regular monitoring of platelet counts in women with Pregnancy Induced Hypertension must be subject of the management protocols.

There is definite statistical difference in values of platelet count in PIH groups when compared with normotensive pregnant women. As PIH is known to land in consumptive coagulopathy, the present study concludes and suggests that the estimation of platelet count offer early, simple, rapid assessments of the disease for its severity and the risk of complications. Therefore, these tests may be considered as screening tests to be routinely performed in antenatal workup of women with PIH.

\section{DISCUSSION}

Hypertensive disorders complicating pregnancy form one of the deadly triads of maternal death along with sepsis and haemorrhage. Pregnancy induced hypertension has been divided into three categories:

\section{- Hypertension alone \\ - Pre-eclampsia \\ - Eclampsia.}

Pre-eclampsia is defined as hypertension (BP>140/90) plus proteinuria $(300 \mathrm{mg}$ or more of urinary protein for $24 \mathrm{hrs}$ or $100 \mathrm{mg} / \mathrm{dl}$ or more in at least two random urine specimens collected 6 or more hours apart).

Importantly the differentiation between mild and severe pre-eclampsia cannot be rigidly pursued because apparently mild disease may progress rapidly to severe disease and one of the signs of severity is thrombocytopenia associated with pre-eclampsia. Maternal thrombocytopenia can be induced acutely by 
pre-eclampsia or may follow the progressive course. The frequency and intensity of maternal thrombocytopenia have shown different results in different studies. The cause of thrombocytopenia is not known; platelet aggregation is increased in pre eclamptic women (Torres and associates). Immunological processes or simply platelet deposition at sites of endothelial damage may be the cause (Pritchard and colleagues). Samuel and colleagues performed direct and indirect anti globulant test and found that platelet bound and circulating platelet bindable immunoglobulin were increased in preeclampsia women and their neonates. They interpreted these findings to suggest platelet surface alterations. Burrows and colleagues reported that platelets from pre eclamptic women were more likely to have platelet associated IgG, even if thrombocytopenia didn't develop. Although, they believed this mechanism implied an autoimmune processing could also be bound to platelets damaged by any mechanism.

Kelton showed that thrombocytopenia with preeclampsia was frequently associated with a prolonged bleeding time. This was true even with normal platelet level. They attributed this to impaired thromboxane synthesis. Kilby and associates and Barr and colleagues found increased intracellular free calcium concentration in platelets from preeclamptic women. Louden and colleagues interpreted this and other evidence to mean that platelets from preeclamptic women are exhausted, that is, platelet aggregation and release are decreased.

The clinical significance of thrombocytopenia, in addition to the obvious impairment in coagulation, is that it reflects the severity of the pathological process. In general, the lower the platelet count, the greater are maternal and fetal morbidity and mortality (Leduc and coworkers, Verhaeghe and colleagues). The addition of elevated liver enzymes to this clinical picture is even more ominous. Weinstein referred to this combination of events as the HELLP syndrome that is, haemolysis $(\mathrm{H})$, Elevated liver enzymes (EL) and low platelets (LP). This study presents data on the platelet count investigated for twenty pregnant women with pregnancy induced hypertension. Significant lower platelet count was observed among pregnant women with PIH compared to individuals from control group.

Preeclampsia is one of the major health problems during pregnancy. It complicates $3 \%-8 \%$ of pregnancies and causes marked increase in perinatal, maternal morbidity, and mortality. ${ }^{13-16}$ Although the exact pathophysiology of preeclampsia is not completely understood, certain factors have been attributed to it, which include deficient trophoblastic invasion of the maternal vascular bed with subsequent reduction of placental blood flow. ${ }^{17,18}$ Placental under perfusion initiates widespread systemic, maternal endothelial dysfunction, and increased vascular permeability. ${ }^{19}$ Coagulation system is activated by the contact of platelets with the injured endothelium leading to increase in consumption as well as bone marrow production of platelets. ${ }^{20}$ Various indices are used to measure platelet functions, for example, the platelet count (PC), mean platelet volume (MPV), the PC to MPV ratio, and platelet distribution width (PDW); PDW measures platelet size distribution. ${ }^{21}$ The utility of different platelets indices as predictors of preeclampsia has been studied previously however, reports in this regard are controversial. 22-33 "Occurrence of hypertension (systolic blood pressure $\geq 140 \mathrm{~mm}$ hg or diastolic blood pressure $\geq 90 \mathrm{~mm} \mathrm{hg}$ ) in the second half of pregnancy (after 20 weeks of gestation) and proteinuria (presence of $300 \mathrm{mg}$ or more of protein in 24 hour urine sample or $\geq 2+$ on dipstick)". ${ }^{34}$ Preeclampsia cases were considered mild or severe according to the diastolic blood pressure of $<110$ or $\geq 110 \mathrm{~mm} \mathrm{hg}$, respectively. ${ }^{35}$

There was no significant difference in PDW in the current study. This goes with the previous findings, where Doğan et al found no significant difference in PDW among women with severe preeclampsia, mild preeclampsia, and healthy controls. ${ }^{26}$ Nonetheless, a significantly higher level of PDW has recently been observed among women with preeclampsia. ${ }^{24,29,36}$

Although, the current study showed no difference in the MPV between the cases and the controls, the utility of MPV in predicting preeclampsia has been shown in several studies. ${ }^{24,26-28,30-32}$ It is worth to mention that Yavuzcan et al observed no significant difference in the MPV between women with severe preeclampsia, healthy pregnant women, and healthy non-pregnant women. ${ }^{33}$ It is noteworthy that some researchers failed to confirm PC and MPV as predictors of preeclampsia, probably because of the differences in the methods and/or equipment used to obtain hemogram. ${ }^{37,38}$

Aside from platelet parameters, there are several biomarkers of preeclampsia including soluble endoglin (seng) or soluble fms-like tyrosine kinase-1 (sflt-1). ${ }^{39}$ One limitation of this study is the lack of a comparative analysis between platelet parameters and seng/sflt-1. However, platelet parameters are simple laboratory markers and easy to check during antenatal care.

\section{ACKNOWLEDGMENTS}

Authors would like to thank Dr. U. S. Shukla for the support during study.

Funding: No funding sources

Conflict of interest: None declared

Ethical approval: The study was approved by the Institutional Ethics Committee

\section{REFERENCES}

1. Sibai B, Dekker G, Kupferminc M. Pre-eclampsia. Lancet. 2005;365(9461):785-99.

2. De Boer K, ten Cate JWn Sturk A, Borm JJ, Treffers PE. Enhanced thrombin generation in normal and 
hypertensive pregnancy. Am J Obstet Gynecol. 1989;160(1):95-100.

3. Prisco D, Cluti G, Falciani M. Haemostatic changes in normal pregnancy. Hematol Rep. 2005;1(10):1-5.

4. Ellenson LH, Pirog EC. The female genital tract. In: Kumar V, Abbas A, Fausto N, Aster J, editkors. Robbins and Cotran Pathologic basis of disease. 8th ed. Philadelphia (PA): Saunders Elsevier; 2010:1055-1056.

5. Redman CW. Current topic: pre-eclampsia and the placenta. Placenta. 1991;12(4):301-8.

6. Burrows RF, Hunter DJ, Andrew M, Kelton JG. A prospective study investigating the mechanism of thrombocytopenia in preeclampsia. Obstet Gynaecol. 1987;70(3 Pt 1):334-8.

7. Vamseedhar A, Srinivasa K, Santhosh K Yatnatti, Suresh DR. Evaluation of platelet indices and platelet counts and their significance in preeclampsia and eclampsia. Int J Biol Med Res. 2011;2(1):425-8.

8. Romero R, Mazor M, Lockwood CJ, Emamian M, Belanger KP, Hobbins JC et al. Clinical significance, prevalence, and natural history of thrombocytopenia in pregnancy-induced hypertension. Am J Perinatol. 1989;6(1):32-8.

9. Shaper AG, Kear J, Macintosh DM, Kyobe J, Njama D. The platelet count,platelet adhesiveness and aggregation and the mechanism of fibrinolytic inhibition in pregnancy and the puerperium. J Obstet Gynaecol Br Commonw. 1968;75(4):433-41.

10. Wallenburg HC, van Kessel PH. Platelet lifespan in normal pregnancy as determined by a nonradioisotopic technique. Br J Obstet Gynaecol. 1978;85(1):33-6.

11. Sill PR, Lind T, Walker W. Platelet values during normal pregnancy. $\mathrm{Br} \mathrm{J}$ Obstet Gynaecol. 1985;92(5):480-3.

12. Gerbasi FR, Bottoms S, Farag A, Mammen E. Increased intravascular coagulation associated with pregnancy. Obstet Gynecol. 1990;75(3 Pt 1):385-9.

13. Adam GK, Bakheit KH, Adam I. Maternal and perinatal outcomes of eclampsia in Gadarif Hospital, Sudan. J Obs Gynaecol. 2009;29(7):619-620.

14. Redman Christopher W, Sargent Ian L. Latest advances in understanding preeclampsia. Sci.2005;308(5728):1592-4.

15. Walker JJ. Pre-eclampsia. Lancet (London, England). 2000;356(9237):1260-5.

16. Anderson UD, Olsson MG, Kristensen KH, Åkerström B, Hansson SR. Review: biochemical markers to predict preeclampsia. Placenta. 2012;33:S42-7.

17. Burton GJ, Woods AW, Jauniaux E, Kingdom JCP. Rheological and physiological consequences of conversion of the maternal spiral arteries for uteroplacental blood flow during human pregnancy. Placenta. 2009;30(6):473-82.

18. Burton GJ, Charnock-Jones DS, Jauniaux E. Regulation of vascular growth and function in the human placenta. Reproduct. 2009;138(6):895-902.
19. Maynard SE, Karumanchi SA. Angiogenic factors and preeclampsia. Semin Nephrol. 2011;31(1):33-46.

20. Juan P, Stefano G, Antonella S, Albana C. Platelets in pregnancy. J Prenat Med. 2011;5(4):90-2.

21. Tzur T, Sheiner E. Is there an association between platelet count during the first trimester and preeclampsia or other obstetric complications later in pregnancy? Hypertens Pregnancy. 2013;32(1):74-82.

22. Altınbas S, Toğrul C, Orhan A, Yücel M, Danısman $\mathrm{N}$. Increased MPV is not a significant predictor for preeclampsia during pregnancy. J Clin Lab Anal. 2012;26(5):403-6.

23. Dundar O, Yoruk P, Tutuncu L, et al. Longitudinal study of platelet size changes in gestation and predictive power of elevated MPV in development of pre-eclampsia. Prenat Diagn. 2008;28(11):1052-6.

24. Freitas LG, Alpoim PN, Komatsuzaki F, Carvalho Md, Dusse LM. Preeclampsia: are platelet count and indices useful for its prognostic? Hematol. 2013;18(6):360-4.

25. Kashanian M, Hajjaran M, Khatami E, Sheikhansari $\mathrm{N}$. Evaluation of the value of the first and third trimester maternal mean platelet volume (MPV) for prediction of pre-eclampsia. Pregnancy Hypertens. 2013;3(4):222-6.

26. Doğan K, Guraslan H, Senturk MB, Helvacioglu C, İdil S, Ekin M. Can platelet count and platelet indices predict the risk and the prognosis of preeclampsia? Hypertens Pregnancy. 2015;34(4):434-42.

27. Han L, Liu X, Li H, Zou J, Yang Z, Han J, et al. Blood coagulation parameters and platelet indices: changes in normal and preeclamptic pregnancies and predictive values for preeclampsia. PLoS One. 2014;9(12):e114488.

28. Kanat-Pektas M, Yesildager U, Tuncer N, Arioz DT, Nadirgil-Koken G, Yilmazer M. Could mean platelet volume in late first trimester of pregnancy predict intrauterine growth restriction and pre-eclampsia? J Obstet Gynaecol Res. 2014;40(7):1840-5.

29. Karateke Atilla, Kurt Raziye Keskin, Baloğlu Ali. Relation of platelet distribution width (PDW) and platelet crit (PCT) to preeclampsia. Ginekol Pol. 2015;86(5):372-5.

30. Moraes D, Munhoz TP, Pinheiro da Costa BE, et al. Immature platelet fraction in hypertensive pregnancy. Plat. 2016;27(4):333-7.

31. Özdemirci Ş, Başer E, Kasapoğlu T, Karahanoğlu E, Kahyaoglu I, Yalvaç S. Predictivity of mean platelet volume in severe preeclamptic women. Hypertens Pregnan. 2016;35(4):474-82.

32. Vilchez G, Londra L, Hoyos LR, Sokol R, BahadoSingh R. Intrapartum mean platelet volume is not a useful predictor of new-onset delayed postpartum pre-eclampsia. Int J Gynaecol Obstet. 2015;131(1):59-62.

33. Yavuzcan A, Caglar M, Ustun Y, Dilbaz S, Yidiz E, Ozbilgec S, et al. Mean platelet volume, neutrophillymphocyte ratio and platelet-lymphocyte ratio in 
severe preeclampsia. Ginekol Pol. 2014;85(3):197203.

34. ACOG technical bulletin. Hypertension in pregnancy. Number 219 - January 1996 (replaces no. 91, February 1986). Committee on Technical Bulletins of the American College of Obstetricians and Gynecologists. Int $\mathbf{J}$ Gynaecol Obstet. 1996;53(2):175-83.

35. ACOG Committee on Obstetric Practice. ACOG practice bulletin. Diagnosis and management of preeclampsia and eclampsia. Number 33, January 2002. American College of Obstetricians and Gynecologists. Int J Gynaecol Obstet. 2002;77(1):67-75.

36. Yang SW, Cho SH, Kwon HS, Sohn IS, Hwang HS. Significance of the platelet distribution width as a severity marker for the development of preeclampsia. Eur J Obstet Gynecol Reprod Biol. 2014;175:107-11.

37. Makuyana D, Mahomed K, Shukusho FD, Majoko F. Liver and kidney function tests in normal and pre- eclamptic gestation - a comparison with nongestational reference values. Cent Afr J Med. 2002;48(5-6):55-9.

38. Ceyhan T, Beyan C, Başer I, Kaptan K, Güngör S, Ifran A. The effect of pre-eclampsia on complete blood count, platelet count and mean platelet volume. Ann Hematol. 2006;85(5):320-2.

39. He Y, Xu B, Song D, Yu F, Chen Q, Zhao M. Correlations between complement system's activation factors and anti-angiogenesis factors in plasma of patients with early/late-onset severe preeclampsia. Hypertens Pregnancy. 2016 35(4):499509.

Cite this article as: Iqbal $\mathrm{S}$, Sharma A. Platelet count and MPV in women with PIH in their third trimester. Int J Reprod Contracept Obstet Gynecol 2019;8:44-9. 